
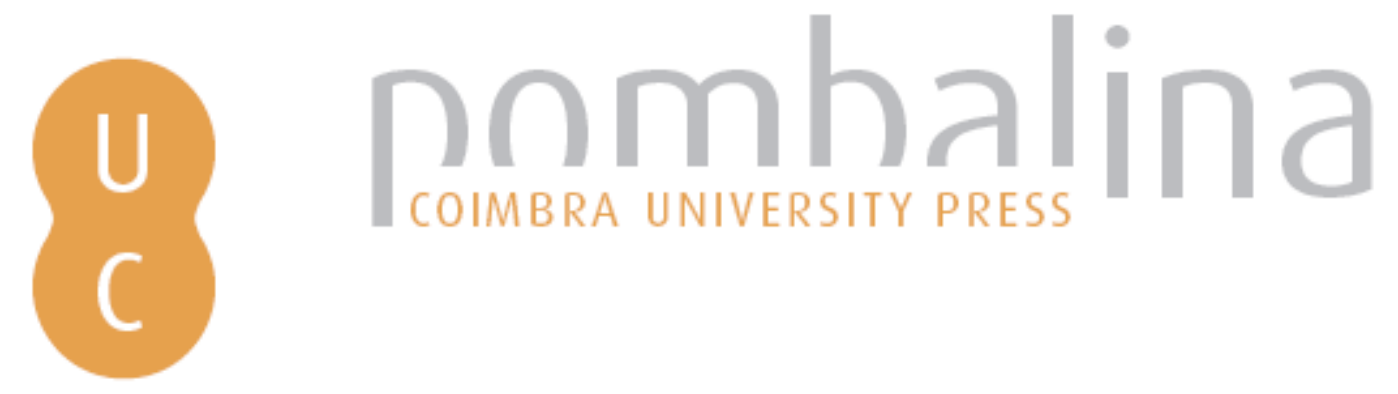

\title{
Análise da influência do interpolador na criação de Modelo Digital de Terreno (MDT): estudo de caso no município de Lajedinho (Bahia, Brasil)
}
Autor(es):
Farias, Renan Xavier; Limoeiro, Milena de Araújo; Reis, Daniel Nadier Cavalcanti; Silva, Mirele Viegas da; Nascimento, Santiago Henrique Anjos Soares

Publicado por: Imprensa da Universidade de Coimbra

URL persistente:

URI:http://hdl.handle.net/10316.2/37081

DOI:

DOI:http://dx.doi.org/10.14195/978-989-26-0983-6_28

Accessed : $\quad$ 26-Apr-2023 02:16:38

A navegação consulta e descarregamento dos títulos inseridos nas Bibliotecas Digitais UC Digitalis, UC Pombalina e UC Impactum, pressupõem a aceitação plena e sem reservas dos Termos e Condições de Uso destas Bibliotecas Digitais, disponíveis em https://digitalis.uc.pt/pt-pt/termos.

Conforme exposto nos referidos Termos e Condições de Uso, o descarregamento de títulos de acesso restrito requer uma licença válida de autorização devendo o utilizador aceder ao(s) documento(s) a partir de um endereço de IP da instituição detentora da supramencionada licença.

Ao utilizador é apenas permitido o descarregamento para uso pessoal, pelo que o emprego do(s) título(s) descarregado(s) para outro fim, designadamente comercial, carece de autorização do respetivo autor ou editor da obra.

Na medida em que todas as obras da UC Digitalis se encontram protegidas pelo Código do Direito de Autor e Direitos Conexos e demais legislação aplicável, toda a cópia, parcial ou total, deste documento, nos casos em que é legalmente admitida, deverá conter ou fazer-se acompanhar por este aviso.

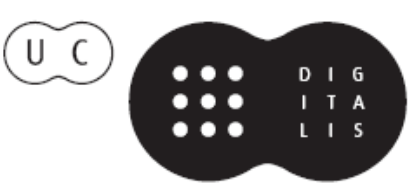




\section{$\forall$ \\ TAS DAS I JORNADAS LUSÓFONAS DE CIÊNCIAS E TECNOLOGIAS DE INFORMAÇÃO GEOGRÁFICA}

Editores

José Gomes dos Santos

Cidália Fonte

Rui Ferreira de Figueiredo

Alberto Cardoso

Gil Gonçalves

José Paulo Almeida

Sara Baptista 


\title{
ARTIGO 28
}

\section{ANÁlise DA INFLUÊNCIA DO INTERPOLADOR NA CRIAÇÃo DE MODELO Digital DE TERRENO（MDT） - ESTUDO DE CASO NO MUNiCípio DE LAJEDINHO, BAHIA, BRASIL}

FARIAS, Renan Xavier ${ }^{1}$; LIMOEIRO, Milena de Araújo ${ }^{2}$; REIS, Daniel Nadier Cavalcanti ${ }^{3}$; SILVA, Mirele Viegas da ${ }^{4}$ \& NASCIMENTO Santiago Henrique Anjos Soares ${ }^{5}$

\footnotetext{
Departamento de Engenharia de Transportes e Geodésia da Universidade Federal da Bahia Escola Politécnica, R. Aristides Novis, 02 - $6^{\circ}$ andar - Federação - CEP: 40210-630, Salvador, Brasil Tel: +55713283-9821; Fax: +557132839821;

1 e-mail: rxfarias@hotmail.com; ${ }^{2}$ e-mail: milenaalimoeiro@gmail.com; 3 e-mail: danielnadier@hotmail.com;

4 e-mail: mirelevgs@gmail.com; 5 e-mail: santiago_anjos@hotmail.com
}

\section{RESUMO}

Esse trabalho descreve o resultado das análises de eficácia dos interpoladores Krigagem, Função de Base Radial e Curvatura Mínima na geração de um modelo digital de terreno pela superfície GRID (Grade Regular). Para comparar a qualidade de cada interpolador foi utilizado como parâmetro o valor do coeficiente de variação da coordenada $Z$ do modelo gerado. Foi analisada também a apresentação visual de cada modelo.

\section{PALAVRAS-CHAVE}

MDT, Krigagem, Função de base radial, Curvatura mínima.

\author{
ANALYSIS OF INTERPOLATOR INFLUENCE IN DIGITAL \\ TERRAIN MODELLING (DTM) GENERATION - A CASE STUDY \\ IN LAJEDINHO DISTRICT (BAHIA, BRAZIL)




\section{AbSTRACT}

This paper describes the results of effectiveness analysis of using the radial basis function, kriging and minimum curvature interpolators to obtain a Digital Terrain Model (DTM). In order to compare the quality of using each interpolator was used as parameters the value of coefficient of variation from each model. The visual presentation of each model also was analyzed.

\section{KEYWORDS}

DTM, TIN, Kriging, Radial basis function, Minimum curvature.

O MDT consiste basicamente na representação computacional do comportamento do relevo de uma superfície topográfica. Na construção de um MDT são usados como parâmetros as coordenadas $\mathrm{X}, \mathrm{Y}$ e $\mathrm{Z}$ de pontos sobre o terreno. O método mais adequado para construção de um MDT depende de como ocorreu à distribuição geométrica de pontos durante a coleta de dados e também do comportamento do relevo do terreno. Os métodos de construção de um MDT mais comuns são os conhecidos como superfícies matriciais ou GRID (Grade Regular) e superfícies TIN (Grade Irregular). As superfícies matriciais ou GRID consiste na coleta dos dados amostrais $(\mathrm{X}, \mathrm{Y})$ com a distribuição espacial dos pontos obtidos em uma direção "constante". Já nas superfícies TIN, a coleta dos pontos amostrais dar-se com espaçamento e distribuição desordenada, apenas em virtude da característica do terreno.

Foram analisados três dos mais populares métodos interpoladores utilizados na construção de um MDT: Krigagem, Função de Base Radial e Curvatura Mínima. Esses foram escolhidos por serem interpoladores comumente utilizados em trabalhos cujos resultados foram satisfatórios. Como, por exemplo, Berveglieri et al. (2011), que utilizou krigagem em MDT's, para comparar casos de isotropia e anisotropia; Silva (2012), que aplicou a Função de Base Radial para análise da Cota de Inundação e Recorrência para a Enseada do Itapocorói e Praia do Morro dos Conventos; e Medina \& Medina (2007), que representou uma Superfície Topográfica com o interpolador Curvatura Mínima, citando suas vantagens e desvantagens.

A técnica da krigagem consiste em estimar valores médios e também uma medida de variabilidade dessa estimativa. Seus pesos são calculados 
com base na distância entre a amostra e o ponto estimado; na continuidade espacial e no arranjo geométrico do conjunto. (BETTINI, 2007). A função de base radial consiste em calcular o valor interpolado com total dependência da distância euclidiana entre os pontos. Método aplicado quando o objetivo é produzir mapas com superfícies suavizadas. E no método de curvatura mínima admite-se que dois pontos adjacentes de um levantamento que eles estejam contidos num mesmo arco, sendo este arco localizado em um plano, no qual se conhece a inclinação e o ângulo de orientação (MEDINA \& QUINTAS, 2008).

A área de estudo é o município de Lajedinho - Bahia, onde ocorreu uma catástrofe ambiental no dia 08 de Dezembro de 2013, quando uma chuva de cerca de $120 \mathrm{~mm}$ atingiu a localidade por, aproximadamente, 3 horas. Como consequência, o rio Saracura, que corta a cidade, transbordou e inundou grande parte da área urbana do município. Dezenas de casas foram arrastadas pelo rio, cerca de 200 famílias ficaram desabrigadas e 17 pessoas morreram. Dois dias após a tragédia a prefeitura da cidade decretou estado de calamidade pública.

O levantamento planialtimétrico foi realizado com a utilização de receptores GNSS de dupla frequência através do método Stop and Go. As coordenadas dos pontos foram determinadas no sistema SIRGAS2000. As altitudes geométricas $(\mathrm{h})$ foram convertidas em altitudes ortométricas (H) com uso do MAPGEO 2010, IBGE. Para a realização do levantamento foram estabelecidos pontos em secções aproximadamente transversais ao rio e que se afastavam entre si em aproximadamente 50 metros. Foram coletados um total de 430 pontos, que cobriram uma área de cerca de $458428 \mathrm{~m}^{2}$. A incerteza posicional de $95 \%$ dos pontos levantados foi de $\pm 2 \mathrm{~mm}$ para as coordenadas planimétricas $(\mathrm{N}, \mathrm{E})$ e de $\pm 4 \mathrm{~mm}$ para as coordenadas altimétricas $(\mathrm{H})$.

Os modelos foram construídos com o auxílio do software Surfer 8, onde foram inseridos os dados das coordenadas tridimensionais dos pontos levantados. São apresentados abaixo os três modelos construídos pelos interpoladores Krigagem (Figura 1), Função de Base Radial (Figura 2) e Curvatura Mínima (Figura 3). 


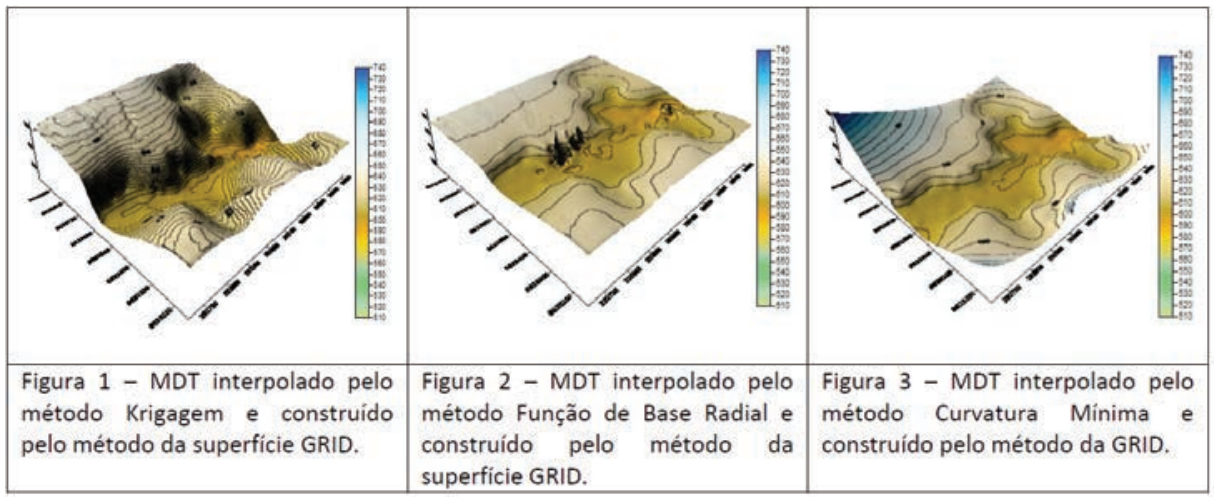

A análise de precisão do modelo gerados foi baseada no valor do coeficiente de variação da coordenada $Z$, uma medida de dispersão relativa comumente utilizada para avaliar a precisão de experimentos. $\mathrm{O}$ coeficiente de variação (cv), é obtido pela razão entre o desvio-padrão $(\sigma)$ e a média ( $\mu$ ). Segundo Gomes (2000), nos experimentos de campo, se o coeficiente de variação for inferior a 10\%, diz que o coeficiente de variação é baixo, ou seja, o experimento tem alta precisão. Os modelos gerados com a utilização dos interpoladores Krigagem, Função de Base Radial e Curvatura Mínima apresentaram, respectivamente, coeficiente de variação no valor de 2,394\%, 2,534\% e 4,173\%. O conhecimento do real comportamento do terreno também é muito importante para a realização de críticas sobre a qualidade do resultado final do modelo. Então, vale ressaltar, que a superfície topográfica da área de estudo apresenta relevo bastante acidentado. Portanto, o interpolador Função de Base Radial não forneceu uma representação visual muito coerente da área, uma vez que suavizou bastante uma área que não possui esse comportamento. O interpolador Curvatura Mínima também gerou um modelo com certa suavização no terreno. Já o interpolador Krigagem, visualmente, foi o mais adequado para a representação da área de estudo, pois foi o que gerou um modelo mais coerente com a conhecida realidade terreno.

Conclui-se que o experimento apresenta alta precisão para o uso de todos os interpoladores testados, pois o coeficiente de variação permaneceu abaixo de $10 \%$ para todos os interpoladores testados, em conformidade com os estudos de Gomes (2000). No entanto, como quanto menor for 
o valor desse coeficiente, melhor é a precisão do experimento, o interpolador Kigragem foi eleito como o mais adequado, por apresentar o menor valor de coeficiente de variação, 2,394\%. E ainda, pela análise visual, esse foi o interpolador que mais se aproximou qualitativamente da superfície topográfica real, demonstrando claramente os locais onde acontece elevação, declividade e suavização do terreno analisado.

\section{BIBLIOGRAFIA}

BERVEGLIERI, Adilson et al. - "Aplicação do Interpolador Krigagem em Modelos Digitais de Terrenos, Comparando-se os Casos de Isotropia e Anisotropio". Anais XV Simpósio Brasileiro de Sensoriamento Remoto, Curitiba, Brasil, 2011, INPE p.7222. Disponível online no endereço url: http://www.dsr. inpe.br/sbsr2011/files/p0693.pdf (Acedido em 09 Março, 2014).

BETTINI, Cláudio (2007) - Conceitos básicos de geoestatística. In: MEIRELLES, M. S. P.; CAMARA, G.; ALMEIDA, C. M. (Ed.). Geomática: modelos e aplicações ambientais. Brasília: Embrapa. cap. 4, p. 193-234.

MEDINA, Alex \& MEDINA, Simone (2007) - "A Representação da Superfície Topográfica Através de Modelos Digitais de Terreno”. Graphica, Curitiba, Paraná. Disponível online no endereço url: http://www.degraf.ufpr.br/ artigos_graphica/AREPRESENTACAODASUPERFICIET OPOGRAFICA.pdf (Acedido em 09 Março, 2014).

MEDINA, Alex \& QUINTAS, Márcia - " O método de interpolação de curvatura mínima”. II Simpósio Brasileiro de Ciências Geodésicas e Tecnologias da Geoinformação, Recife, PE, 2008. Disponível online no endereço url: http:// www.ufpe.br/cgtg/SIMGEOII_CD/Organizad o/cart_sig/172.pdf (Acedido em 09 Março, 2014).

MILLER \& LAFLAMME apud DRUZINA, Aline. Dissertação de Mestrado, 2007. Disponível online no endereço urlhttp://www.ufrgs.br/srm/ppgsr/publicacoes/Dissert_AlineDruzina.pdf (Acedido em 09 Março, 2014).

SILVA, Guilherme - "Cota de Inundação e Recorrência para a Enseada do Itapocorói e Praia do Morro dos Conventos, Santa Catarina". 2012. Disponível online no endereço url: http://www.lume.ufrgs.br/bitstream/handle/10183/56330/000860662.pdf?sequence=1 (Acedido em 25 Março, 2014) 
Série Documentos

Imprensa da Universidade de Coimbra

Coimbra University Press

2015

- U M

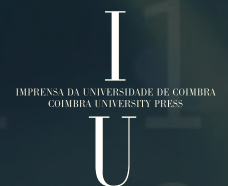

